\title{
Minimal Adhesions to ePTFE Mesh After Laparoscopic Ventral Incisional Hernia Repair: Reoperative Findings in 65 Cases
}

\author{
Richard H. Koehler, MD, Dennis Begos, MD, Dieter Berger, MD, Steve Carey, MD, Karl LeBlanc, MD, \\ Adrian Park, MD, Bruce Ramshaw, MD, Roy Smoot, MD, Guy Voeller, MD
}

\begin{abstract}
Objectives: Laparoscopic ventral incisional hernia repair involves intraabdominal placement of a synthetic mesh, and the possibility of formation of severe visceral adhesions to the prosthesis is a principal concern. Little clinical information based on reoperative findings is available about adhesions to biomaterials placed intraabdominally. We conducted a multiinstitutional study of adhesions to implanted expanded polytetrafluoroethylene (ePTFE) mesh at reoperation in patients who had previously undergone laparoscopic incisional hernia repair done with the same mesh implantation technique.
\end{abstract}

Methods: Nine surgeons retrospectively assessed the severity of adhesions to ePTFE mesh at reoperation in 65 patients. For each case, adhesions were assigned a score of 0 to 3, with 0 indicating no adhesions and 3 severe adhesions.

Results: The mean time from mesh implantation to reoperation was 420 days (range, 2 to 1739 days). No adhesions were observed in 15 cases. Forty-four cases received an adhesion score of 1 , and 6 cases a score of 2; no scores of 3 were assigned. Thus, 59 patients (91\%) had either no or filmy, avascular adhesions. No enterotomies occurred during adhesiolysis.

Conclusions: In this large series of reoperations after laparoscopic incisional hernia repair, no or minimal formation of adhesions to implanted ePTFE mesh was observed in $91 \%$ of cases, and no severe cohesive adhesions were found. Comparative analyses of newer mate-

Springfield Hospital, Springfield, Vermont (Dr Koehler).

Lawrence Memorial Hospital, Lawrence, Massachusetts (Dr Begos).

The StadtKlinik, Baden-Baden, Germany (Dr Berger).

Nanticoke Surgical, Seaford, Delaware (Drs Carey, Smoot)

Surgical Specialty Group, Baton Rouge, Louisiana (Dr LeBlanc).

University of Kentucky, Lexington, Lexington, Kentucky (Dr Park)

Emory University, Atlanta, Georgia (Dr Ramshaw).

University of Tennessee, Memphis, Tennessee (Dr Voeller).

Address reprint requests to: Richard H. Koehler, MD, Springfield Hospital, 29 Ridgewood Rd, Springfield, VT 05156. Telephone: 802885 3334, Fax: 8028853305 , islandmd@vermontel.net

(c) 2003 by JSLS, Journal of the Society of Laparoendoscopic Surgeons. Published by the Society of Laparoendoscopic Surgeons, Inc rials based on clinical reoperative findings are warranted to assess the safety of intraabdominally placed meshes.

Key Words: Ventral incisional hernia, Adhesions, Laparoscopy, Polytetrafluoroethylene.

\section{INTRODUCTION}

The need for reinforcement of the abdominal wall by implantation of synthetic materials during repair of abdominal incisional hernias is well established. ${ }^{1-4}$ Moreover, because early use of various biomaterials in ventral incisional hernia repair resulted in some serious complications, including fistulization due to adhesions, ${ }^{5-7}$ it is clear that avoiding contact between the mesh and viscera is desirable. $2,3,8,9$ In laparoscopic incisional herniorrhaphy, however, first described by LeBlanc and Booth in $1993,{ }^{10}$ placement of the mesh in the intraabdominal position is necessary. Thus, this procedure requires a biomaterial that provides both adequate strength and a minimal risk of severe adhesion formation that could result in bowel obstruction or fistula development.

Numerous studies of the formation of adhesions to biomaterials placed intraabdominally have been conducted in animals, but few investigations of this issue have been based on information obtained at reoperation in patients. Moreover, no large study has examined reoperative observations pertaining to adhesions to a biomaterial after laparoscopic incisional hernia repair specifically. Therefore, we conducted a retrospective review of findings at reoperation in patients who had undergone such a repair and in whom a 1-mm-thick expanded polytetrafluoroethylene (ePTFE) dual-surface mesh (DualMesh, W.L. Gore \& Associates, Flagstaff, AZ) had been implanted during the repair.

\section{METHODS}

Records of adult patients who had undergone a laparoscopic repair of a ventral incisional hernia including placement of DualMesh intraabdominally between April 1993 and April 2001 were reviewed after institutional IRB approval. Patients who subsequently underwent abdom- 
inal reoperation for various indications, during the same time period, were selected for retrospective review.

The technique used for initial mesh placement was essentially the same in all cases and was described in detail previously. ${ }^{11}$ Briefly, the mesh was placed laparoscopically in the intraabdominal onlay position and secured with sutures as well as circumferentially placed $5-\mathrm{mm}$ titanium tacks. In some cases, titanium staples were used around the periphery.

For the review, the 9 surgeons (authors) participating in the study completed a questionnaire about findings at reoperation in each case meeting the criteria described above. The questionnaire included a section asking the surgeons to score, retrospectively on the basis of the operative reports, the adhesions encountered according to the severity scale described by Diamond. ${ }^{12}$ Thus, a score of 0 was to be assigned if no adhesions were present; a score of 1 if filmy, avascular adhesions were present; a score of 2 for vascular or dense adhesions, or both; and a score of 3 for cohesive adhesions. In all cases, the same surgeon who performed the original repair completed the questionnaire on findings at reoperation. Data from the questionnaires were compiled according to adhesion score and surgeon. In addition, patient demographics, time from initial mesh implantation, and reason for reoperation were included.

\section{RESULTS}

Sixty-five patients were included in the study. There were 35 females and 30 males, with ages ranging from 27 to 86 (average age, 55 years). The mean time between the laparoscopic repair including mesh implantation and reoperation was 420 days (range, 2 to 1739 days). Seventeen of the patients underwent reoperation because of hernia recurrence because of either mesh dislodgment due to inadequate fixation or infection necessitating removal of the mesh. Ten patients required reoperation because of complications, including early infection, delayed enterotomy, and bowel obstruction; none of the cases of obstruction were due to adhesions to the prosthesis. The remaining 38 patients had a new diagnosis requiring surgery.

The adhesion scores reported by the surgeons are shown in Table 1. No adhesions to the mesh were observed in 15 cases (23\%). In 44 cases (68\%), the adhesions observed were filmy and avascular (score of 1). Vascular or dense adhesions, or both, (score of 2) were found in 6 cases (9\%). No adhesion scores of 3 were assigned. No significant difference was noted in adhesion scores with respect to implant duration, in particular with respect to patients with a score of 0 compared with those with a score of 2 .

Therefore, at reoperation in $91 \%$ of patients who had undergone laparoscopic abdominal hernia repair, adhesions were either not present or were filmy and avascular. All the dense adhesions (adhesion score 2) involved omentum only, and most involved only the exposed portions of the titanium tacks. Dissection of adhesions to the mesh required little effort, and no enterotomies occurred during adhesiolysis against the ePTFE. One patient developed a delayed enterotomy after extensive adhesions to a previous polypropylene patch; this same patient had minimal filmy adhesions to the ePTFE index patch.

Representative photographs obtained at reoperation are shown in Figures 1 through $\mathbf{4}$. In early reoperations (fewer than 14 days after the original repair), no adhesions to the mesh were observed (Figure 1), although in several cases, adhesions had already formed to the

Table 1.

Adhesion Scores* for 65 Patients at Reoperation, According to Surgeon

\begin{tabular}{llll}
\hline Surgeont & 0 & 1 & 2 \\
\hline 1 & 1 & 6 & 3 \\
2 & 4 & 4 & 0 \\
3 & 1 & 7 & 1 \\
4 & 4 & 5 & 0 \\
5 & 0 & 9 & 0 \\
6 & 3 & 5 & 0 \\
7 & 2 & 3 & 1 \\
8 & 0 & 5 & 1 \\
\hline Total & 15 & 44 & 6
\end{tabular}

*Adhesions were scored according to the severity criteria of Diamond ${ }^{12}$; thus, 0 indicated no adhesions; 1, filmy, avascular adhesions; 2, vascular or dense adhesions, or both; and 3, cohesive adhesions. No adhesions received a score of 3 . Values are numbers of patients with each score.

†Nine surgeons participated in the study, but 2 surgeons in the same practice reported their results together. 


\section{JSLS}

exposed titanium tacks (Figure 2). At reoperations done 2 weeks or longer after the laparoscopic repair, a "neoperitoneum" across the mesh was frequently observed (Figure 3). This membrane could be removed intact from the underlying mesh surface (Figure 4).

\section{DISCUSSION}

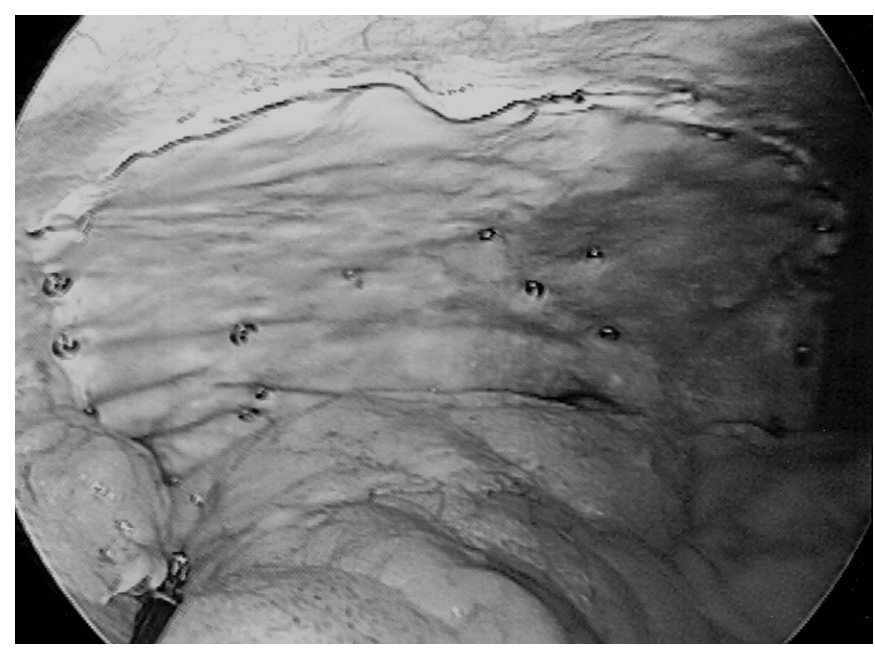

Figure 1. Appearance of DualMesh 5 days after implantation in a patient in whom an incarcerated inguinal hernia developed 5 days after repair of a previously incarcerated flank hernia in a nephrectomy incision. No adhesions to the mesh are present.

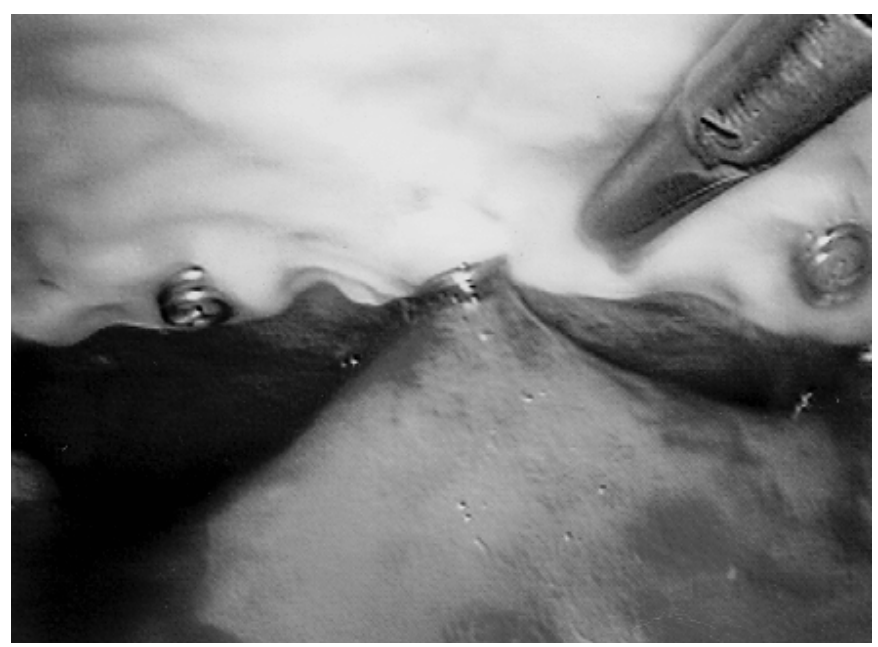

Figure 2. Adhesion of viscera to titanium tack 12 days after incisional hernia repair in a patient in whom a small-bowel obstruction developed as a result of enteroenteric adhesions unrelated to the repair. No adhesions to the DualMesh are present.
In a multiinstitutional series of 65 reoperations after laparoscopic ventral incisional hernia repair in which the same technique for mesh implantation had been used in all patients, we observed either no adhesions to DualMesh or filmy, avascular adhesions in 59 (91\%) cases. These findings are in agreement with the few other clinical reports of reoperations after implantation of ePTFE in laparoscopic incisional hernia repair. Gillion et

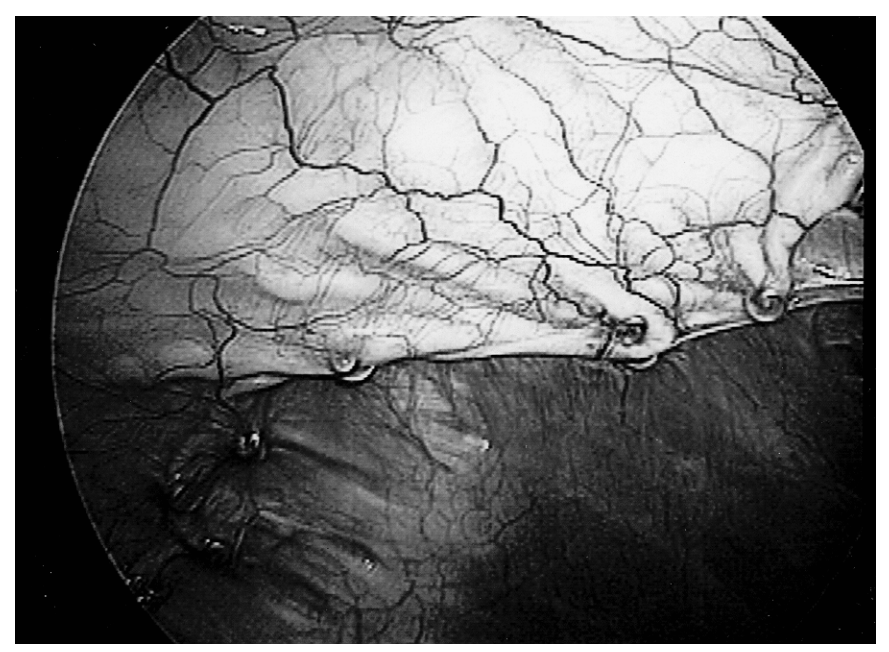

Figure 3. Appearance of DualMesh at reoperation 20 months after implantation. A neoperitoneum and extensive vascularization are present across the surface of a large piece of mesh (18 $\mathrm{cm} \times 24 \mathrm{~cm}$ ).

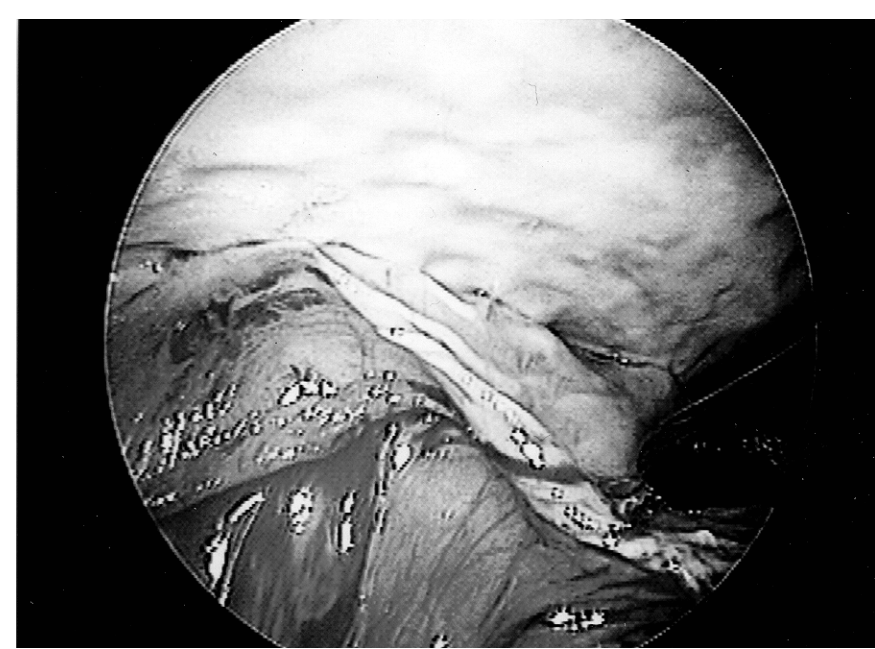

Figure 4. Removal of neoperitoneum from the DualMesh surface in the same patient as in Figure 2. DualMesh resulted in no adhesion formation. 
al13 observed no adhesions during 6 reoperations after ePTFE had been placed in the intraperitoneal or extraperitoneal position for repair of incisional hernias of the anterolateral abdominal wall. Koller at el ${ }^{14}$ found minimal adhesions to ePTFE during 2 reoperations.

We also observed, in patients in whom the DualMesh had been implanted for greater than 2 weeks, a well-vascularized "neoperitoneum" across the entire mesh surface, similar to that described by Bellon et al15,16 in experimental and clinical studies of ePTFE, by Gillion et al ${ }^{13}$ in their series of clinical reoperations, and by Carbajo et al, ${ }^{17}$ who observed complete reperitonealization of DualMesh in the 2 reoperations they described.

Avoiding contact between prosthetic mesh and viscera to minimize formation of adhesions after ventral incisional hernia repair was a central concern even before development of the laparoscopic approach. In reports describing open repair, Stoppa ${ }^{2}$ and Wantz ${ }^{3}$ advised that contact between an intraperitoneally placed prosthesis (polyester) and the viscera should be prevented by covering the prosthesis with omentum (if possible) or by inserting an absorbable synthetic prosthesis. Condon ${ }^{9}$ noted that because of the intense inflammatory reaction caused by polypropylene mesh, the bowel should be protected from that material. In a review of their experience with the Stoppa technique, Temudom et al ${ }^{18}$ emphasized the importance of positioning autogenous tissue between the bowel and the surface of polypropylene mesh. Some authors, ${ }^{19}$ however, still recommend direct intraabdominal placement of polyester mesh.

Numerous reports have been made about complications resulting from placement of mesh in contact with the viscera. Many of these $5,6,20-22$ described erosion or fistula formation occurring with the use of polypropylene mesh in trauma cases in which extensive contamination was present, the mesh was in contact with the viscera by necessity, and no tissue covered the mesh externally. However, fistula formation after implantation of various biomaterials in the abdominal wall has also been observed in several nontrauma cases.7,22

With the laparoscopic approach to abdominal incisional hernia repair, peritoneal dissection and covering of the mesh is often impossible with true incisional hernias. Holzman et al23 observed that efforts to separate the peritoneum of the hernia sac might produce a large peritoneal defect and leave the mesh exposed. They suggested omental interposition, as did Franklin et al, ${ }^{24}$ and oth- ers have reported that this technique can reduce or eliminate adhesion of viscera to polypropylene. ${ }^{20,22}$ However, in the series of 19 reoperative cases described by Franklin et al,24 in which this omental protection technique had presumably been used during the previous hernia repair, one third of patients had severe adhesions to the polypropylene mesh.

Moreover, covering mesh with omentum can be difficult because of the large defects being repaired laparoscopically. Park et al, ${ }^{25}$ in their early experience with laparoscopic repair of large incisional hernias, used mesh sizes as large as $530 \mathrm{~cm}^{2}$. Koehler and Voeller ${ }^{26}$ reported that $38 \%$ of their cases involved mesh of at least $18 \mathrm{~cm} \mathrm{x} 24$ $\mathrm{cm}$ and that $9 \%$ required 2 pieces of mesh sewn together. Other reports of laparoscopic repairs reveal similar experiences. ${ }^{11,17,27}$

If an absorbable mesh is inserted along with a nonabsorbable prosthesis to prevent temporary contact between the nonabsorbable material and the viscera-a method recommended by Wantz ${ }^{3}$ and others ${ }^{28}$ - the time during which peritoneal coverage is provided is a concern. One study of adhesion formation in a rat model suggested that most adhesions were fully developed by 7 days after implantation of mesh29; however, Amid30 expressed caution against such results that suggest a temporary barrier is needed for only a short time. No clinical studies have been based on findings at reoperation indicating that absorbable barriers are effective, and Luijendijk et $\mathrm{al}^{4}$ stated that neither experimental nor clinical studies have provided conclusive information on the efficacy of interposition of polyglactin mesh in preventing adhesions, bowel obstruction, and fistulas. We believe that placement of an absorbable barrier to a large mesh that is subsequently fixed to the moving environment of the anterior abdominal wall represents an improbable solution.

In contrast to the experience with some other materials, early experiences with ePTFE showed that it was apparently effective in limiting formation of adhesions on the visceral side, but limited fascial surface ingrowth was a concern. DualMesh was developed to address this concern. This mesh is composed of 2 layers of ePTFE with different surface characteristics; one layer has a "smooth," nonporous surface to be placed against the viscera to limit adhesions and the other has a "rough" surface with large interstices in the material $(22 \mu \mathrm{m})$ to encourage tissue ingrowth. DualMesh has so far been 
used in more than 1000 laparoscopic ventral and incisional hernia repairs, ${ }^{11,26,27,31,32}$ with good results with respect to recurrences and complications. The current study of 65 reoperations supports the assumption that no or minimal adhesions result from the use of DualMesh in such procedures. Interestingly, we observed no adhesions to this type of mesh in patients in whom adhesions to titanium tacks developed, a finding indicating that even in patients with a possible tendency to form adhesions, DualMesh serves to limit such formation.

Although this study has the limitation of being a retrospective analysis of operative findings, all the surgeons involved had extensive experience with laparoscopic repair of incisional hernias and with clinical studies of this procedure, including assessments of the adhesiogenic properties of biomaterials. Any reoperations necessary after incisional hernia repairs were therefore analyzed and described carefully in operative reports, and particular attention was paid to findings regarding adhesions.

This study, like several others, used "Diamond scores" to describe the severity of adhesions; we did not use the quantitative portion of the Diamond criteria (ie, determination of the percentage of surface area involved with adhesions), because our primary interest was to assess how difficult it was to separate the omentum or viscera during adhesiolysis. We think, however, that Diamond scores have important limitations in representing operative situations. For example, easily sweeping aside several hundred square centimeters of filmy adhesions may take less than a minute, without incident, whereas removing a few square centimeters of dense adhesions can lead to an enterotomy. In addition, making comparisons of studies using Diamond scores is difficult because of varying assumptions about what constitutes mild and severe adhesions. Therefore, we favor an adhesion scale that reflects the ease or difficulty with which adhesiolysis is accomplished. That described by Zuhlke et al33 is close to achieving this goal. On this scale, 1 denotes adhesions that are filmy and easy to separate; 2 , adhesions that may be removed by blunt dissection, but partial sharp dissection may be required; 3 , adhesions that are strongly attached and can be removed by sharp dissection only; and 4, adhesions that are so severe that injury to an organ is likely during dissection. Application of this scale to the reoperative findings in our study would result in all cases scored as 0 or 1 according to the Diamond scale being assigned a "Zuhlke score" of 1 .

\section{CONCLUSIONS}

Laparoscopic ventral incisional hernia repair requires placement of nonabsorbable mesh in an intraabdominal location. Many studies of intraabdominal placement of synthetic meshes in animals have been done to assess the risk of visceral adhesion to these biomaterials, but little information has been available on reoperative findings after mesh implantation in patients. In this study, we investigated the use of 1 type of ePTFE mesh in a retrospective review of reoperations in patients in whom the technique used for mesh placement during laparoscopic repair of ventral incisional hernias was identical. Our findings suggest that DualMesh is effective in minimizing, and often eliminating, visceral adhesion formation after this repair.

Research is continuing on new prostheses for abdominal wall hernia repair, especially meshes composed of a combination of absorbable and nonabsorbable materials. Clinical reoperative findings evaluated with the use of relevant adhesion-scoring systems will be important in determining the comparative effectiveness of these new materials in preventing formation of visceral adhesions.

\section{References:}

1. Hesselink VJ, Luijendijk RW, de Wilt JH, Heide R, Jeekel J. An evaluation of risk factors in incisional hernia recurrence. Surg Gynecol Obstet. 1993;176:228-234.

2. Stoppa RE. The treatment of complicated groin and incisional hernias. World J Surg. 1989;13:545-554.

3. Wantz GR. Incisional hernioplasty with Mersilene ${ }^{\circledR}$. Surg Gynecol Obstet. 1991;172:129-137.

4. Luijendijk RW, Hop WC, van den Tol MP, et al. A comparison of suture repair with mesh repair for incisional hernia. $N$ Engl J Med. 2000;343:392-398.

5. Kaufman Z, Engelberg M, Zager M. Fecal fistula: a late complication of Marlex® mesh repair. Dis Colon Rectum. 1981;24: 543-544.

6. Schneider R, Herrington JL Jr, Granda AM. Marlex mesh in repair of a diaphragmatic defect later eroding into the distal esophagus and stomach. Am Surg. 1979;45:337-339.

7. Leber GE, Garb JL, Alexander AI, Reed WP. Long-term complications associated with prosthetic repair of incisional hernias. Arch Surg. 1998;133:378-382.

8. Morris-Stiff GJ, Hughes LE. The outcomes of nonabsorbable mesh placed within the abdominal cavity: literature review and clinical experience. J Am Coll Surg. 1998;186:352-367. 
9. Condon RE. Incisional hernia. In: Nyhus LM, Condon RE, eds. Hernia. 4th ed. Philadelphia, PA: Lippincott; 1995:319-336.

10. LeBlanc KA, Booth WV. Laparoscopic repair of incisional abdominal hernias using expanded polytetrafluoroethylene: preliminary findings. Surg Laparosc Endosc. 1993;3:39-41.

11. Heniford BT, Park A, Ramshaw BJ, Voeller G. Laparoscopic ventral and incisional hernia repair in 407 patients. J Am Coll Surg. 2000;190:645-650.

12. Diamond MP. Reduction of adhesions after uterine myomectomy by Seprafilm membrane (HAL-F): a blinded, prospective, randomized, multicenter clinical study. Fert Steril. 1996;66:904910.

13. Gillion J-F, Begin G-F, Marecos C, Fourtanier G. Expanded polytetrafluoroethylene patches used in the intraperitoneal or extraperitoneal position for repair of incisional hernias of the anterolateral abdominal wall. Am J Surg. 1997;174:16-19.

14. Koller R, Miholic J, Jakl RJ. Repair of incisional hernias with expanded polytetrafluoroethylene. Eur J Surg. 1997;163:261-266.

15. Bellon JM, Contreras LA, Bujan J, Pascual G, Carrera-San Martin A. Effect of relaparotomy through previously integrated polypropylene and polytetrafluoroethylene experimental implants in the abdominal wall. J Am Coll Surg. 1999;188:466-472.

16. Bellon JM, Contreras LA, Sabater C, Bujan J. Pathologic and clinical aspects of repair of large incisional hernias after implant of a polytetrafluoroethylene prosthesis. World J Surg. 1997;21: 402-407.

17. Carbajo MA, del Olmo JC, Blanco JI, et al. Laparoscopic treatment of ventral abdominal wall hernias: preliminary results in 100 patients. JSLS. 2000;4:141-145.

18. Temudom T, Siadati M, Sarr MG. Repair of complex giant or recurrent ventral hernias by using tension-free intraparietal prosthetic mesh (Stoppa technique): lessons learned from our initial experience (fifty patients). Surgery. 1996;120:738-744.

19. Arnaud J-P, Tuech J-J, Pessaux P, Hadchity Y. Surgical treatment of postoperative incisional hernias by intraperitoneal insertion of Dacron mesh and an aponeurotic graft: a report on 250 cases. Arch Surg. 1999;134:1260-1262.

20. Brandt CP, McHenry CR, Jacobs DG, Piotrowski JJ, Priebe PP. Polypropylene mesh closure after emergency laparotomy: morbidity and outcome. Surgery. 1995;118:736-741.
21. Nagy KK, Fildes JJ, Mahr C, et al. Experience with three prosthetic materials in temporary abdominal wall closure. $\mathrm{Am}$ Surg. 1996;62:331-335.

22. Karakousis CP, Volpe C, Tanski J, Colby ED, Winston J, Driscoll DL. Use of a mesh for musculoaponeurotic defects of the abdominal wall in cancer surgery and the risk of bowel fistulas. J Am Coll Surg. 1995;181:11-16.

23. Holzman MD, Purat CM, Reintgen K, Eubanks S, Pappas TN. Laparoscopic ventral and incisional hernioplasty. Surg Endosc. 1997;11:32-35.

24. Franklin ME, Dorman JP, Glass JL, Balli JE, Gonzalez JJ. Laparoscopic ventral and incisional hernia repair. Surg Laparosc Endosc. 1998;8:294-299.

25. Park A, Gagner M, Pomp A. Laparoscopic repair of large incisional hernias. Surg Laparosc Endosc. 1996;6:123-128.

26. Koehler RH, Voeller G. Recurrences in laparoscopic incisional hernia repairs: a personal series and review of the literature. JSLS. 1999;3:293-304.

27. LeBlanc KA, Booth WV, Whitaker JM, Bellanger DE. Laparoscopic incisional and ventral herniorrhaphy in 100 patients. Am J Surg. 2000;180:193-197.

28. Naim JO, Pulley D, Scanlan K, Hinshaw JR, Lanzafame RJ. Reduction of postoperative adhesions to Marlex mesh using experimental adhesion barriers in rats. J Laparoendosc Surg. 1993;3:187-190.

29. Baptista ML, Bonsack ME, Felemovicius I, Delaney JP Abdominal adhesions to prosthetic mesh evaluated by laparoscopy and electron microscopy. J Am Coll Surg. 2000; 190:271-280

30. Amid PK. Intraabdominal adhesions to prosthetic mesh. $J$ Am Coll Surg. 2000;191:342-343.

31. Toy FK, Bailey RW, Carey S, et al. Prospective, multicenter study of laparoscopic ventral hernioplasty: preliminary results. Surg Endosc. 1998;12:955-959.

32. Kyzer S, Alis M, Aloni Y, Charuzi I. Laparoscopic repair of postoperation ventral hernia: early postoperation results. Surg Endosc. 1999; 13:928-931.

33. Zuhlke HV, Lorenz EM, Straub EM, Savvas V. Pathophysiology and classification of adhesions [in German]. Langenbecks Arch Chir Suppl II Verh Dtsch Ges Chir. 1990;345:1009-1016. 